\title{
Temperature Field Calculation and Analysis within Steel Tube Reinforced Columns
}

\author{
Lei $\mathrm{Xu}^{*}$ and Jiangang Sun
}

School of Civil \& Architectural Engineering, DaLian Nationalities University, DaLian 116600, China

\begin{abstract}
The temperature field analysis method of steel tube reinforced columns under fire by finite element analysis software ABAQUS is proposed in this paper. The theoretical method is validated by tests, and the calculated results agree well with those of tests. On the basis of that, the influencing laws of temperature rising time; section perimeter; steel reinforcement ratio and sectional core area ratio on temperature field are discussed. It has been found that the surface temperatures of steel tube reinforced columns increase obviously with temperature rising time, and the temperatures of steel tubes and core concrete increase slowly. The effects of section size and sectional core area ratio on temperature field are significant, but steel ratio has very little effect on temperature both of steel tube and of sectional center. These achievements make it possible to study further theoretical study on the mechanic performance of steel tube reinforced concrete columns in fire.
\end{abstract}

Keywords: Steel Tubes Reinforced Columns, ABAQUS, Elevated Temperature, Boundary Condition, Temperature Field.

\section{INTRODUCTION}

Steel tube reinforced concrete (The "Steel tube reinforced concrete" will be abbreviated as STRC for the citation purpose.) columns are a form of steel reinforced concrete structures. They place steel tubes in reinforced concrete, and make steel pipe, bars (longitudinal bars and stirrups) and concrete work cooperatively against external load. The typical cross-sections of STRC are showen in Fig. (1). In spite of owning general advantages of conventional SRC constructions, STRC have also several benefits. One of the main benefits is: steel evenly distributed near the cross section periphery, not only can make the best use of steel tubes, but also can strengthen cross section corner under biaxial load. In addition, because of the confinement between the steel tube and core concrete, a substantial increase in load bearing capacity of the columns and much better endurance characteristics can be obtained. STRC also have a higher fire resistance, which partly due to the confinement between the steel tube and core concrete, and partly due to the insulation of outer layer reinforced concrete which make core concrete filled steel tubes have lower temperatures. Another benefit is that steel tubes are easy to fabricate and convenient to construction. These advantages have led to the increased use of such columns in many highrise buildings.

An important criterion for the design of steel tube reinforced concrete columns, besides the serviceability and critical load bearing capacity, is fire resistance. As stated above, STRC can be expected owning a higher fire resistance than conventional SRC and CFST columns. But

*Address correspondence to these authors at the School of Civil \& Architectural Engineering, DaLian Nationalities University, DaLian 116600, China; Tel: +86-411-87612390; Fax: +86-411-87618179;

E-mails: xulei@dlnu.edu.cn,xulgb@163.com the studies on the STRC structures are also rare either in China or foreign. Research on the excellent mechanical performance STRC shown under and after fire relative to SRC, CFST and steel structures is much less. Only Zhejiang University has experimentally investigated on the temperature fields under high temperature and the bearing capacity after fire of the structure in China [1]. So the application and popularization of the structures are restraint because of the lack of design codes. In order to reveal the mechanical performance and destructive mechanism of STRC under and after high temperature, the temperature fields within STRC columns must be determined at first.
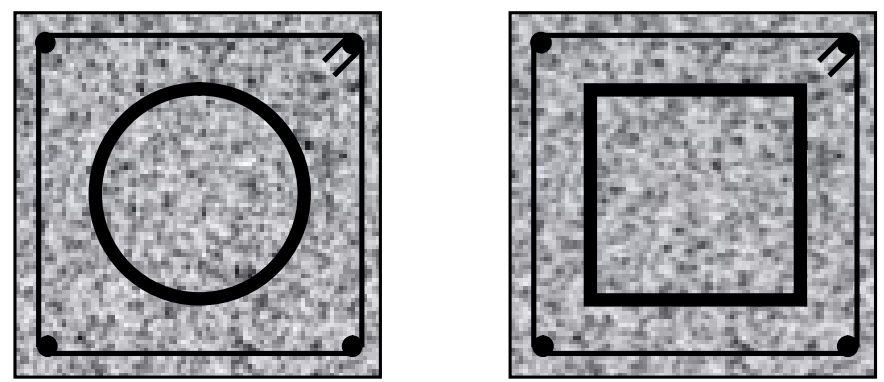

Fig. (1). The typical cross-sections of STRC columns.

This paper is concerned with temperature fields for this kind of members. A nonlinear finite element analysis model by ABAQUS software has been established to calculate the temperature field at different heating time. The theoretical predictions are in good agreement with the experimental data. The theoretical model was used to analyze the influences of sectional dimension, sectional steel ratio and sectional core area ratio on temperature field. 


\section{HEAT PROPERTIES OF MATERIALS}

The temperature field analysis depends on the heat properties of steel and concrete, including density, specific heat and thermal conductivity. The latest properties for steel and concrete published by Lie (1994) [2] are adopted in this paper.

\subsection{Heat Properties of Steel}

(1) Thermal conductivity

$$
\lambda_{\mathrm{s}}=\left\{\begin{array}{cc}
-0.022 \mathrm{~T}+48\left(\mathrm{~W} / \mathrm{m} \cdot{ }^{\circ} \mathrm{C}\right) & 0^{\circ} \mathrm{C} \leq T \leq 900^{\circ} \mathrm{C} \\
28.2\left(\mathrm{~W} / \mathrm{m} \cdot{ }^{\circ} \mathrm{C}\right) & T>900^{\circ} \mathrm{C}
\end{array}\right.
$$

(2) Specific heat and density

$$
\begin{array}{cc}
\rho_{\mathrm{s}} c_{\mathrm{s}}=(0.004 T+3.3) \times 10^{6}\left(\mathrm{~J} / \mathrm{m}^{3} \cdot{ }^{\circ} \mathrm{C}\right) & 0^{\circ} \mathrm{C} \leq T \leq 650^{\circ} \mathrm{C} \\
\rho_{\mathrm{s}} c_{\mathrm{s}}=(0.068 T-38.3) \times 10^{6}\left(\mathrm{~J} / \mathrm{m}^{3} \cdot{ }^{\circ} \mathrm{C}\right) & 650^{\circ} \mathrm{C}<T \leq 725^{\circ} \mathrm{C} \\
\rho_{\mathrm{s}} c_{\mathrm{s}}=(-0.086 T+73.35) \times 10^{6}\left(\mathrm{~J} / \mathrm{m}^{3} \cdot{ }^{\circ} \mathrm{C}\right) & 725^{\circ} \mathrm{C}<T \leq 800^{\circ} \mathrm{C} \\
\rho_{s} c_{\mathrm{s}}=4.55 \times 10^{6}\left(\mathrm{~J} / \mathrm{m}^{3} \cdot{ }^{\circ} \mathrm{C}\right) & T>800^{\circ} \mathrm{C}
\end{array}
$$

(3) Coefficient of thermal expansion

$$
\left.\begin{array}{cc}
\alpha_{\mathrm{s}}=(0.004 T+12) \times 10^{-6}\left(\mathrm{~m} / \mathrm{m} \cdot{ }^{\circ} \mathrm{C}\right) & T<1000^{\circ} \mathrm{C} \\
\alpha_{\mathrm{s}}=16 \times 10^{-6}\left(\mathrm{~m} / \mathrm{m} \cdot{ }^{\circ} \mathrm{C}\right) & T \geq 1000^{\circ} \mathrm{C}
\end{array}\right\}
$$

\subsection{Heat Properties of Concrete}

(1) Thermal conductivity

$$
\begin{aligned}
& k_{c}=\left\{\begin{array}{cc}
1.355 & \left(\mathrm{~W} / \mathrm{m} \cdot{ }^{\circ} \mathrm{C}\right) \\
-0.001241 T+1.7162 & \left(\mathrm{~W} / \mathrm{m} \cdot{ }^{\circ} \mathrm{C}\right)
\end{array}\right. \\
& 0^{\circ} \mathrm{C} \leq T \leq 293^{\circ} \mathrm{C} \\
& \quad T>293^{\circ} \mathrm{C}
\end{aligned}
$$

(2) Specific heat and density

$$
\begin{array}{cc}
\rho_{c} c_{c}=2.566 \times 10^{6}\left(\mathrm{~J} / \mathrm{m}^{3} \cdot{ }^{\circ} \mathrm{C}\right) & 0^{\circ} \mathrm{C} \leq T \leq 400^{\circ} \mathrm{C} \\
\rho_{c} c_{c}=(0.1765 T-68.034) \times 10^{6}\left(\mathrm{~J} / \mathrm{m}^{3} \cdot{ }^{\circ} \mathrm{C}\right) & 400^{\circ} \mathrm{C}<T \leq 410^{\circ} \mathrm{C} \\
\rho_{c} c_{c}=(-0.05043 T+25.00671) \times 10^{6}\left(\mathrm{~J} / \mathrm{m}^{3} \cdot{ }^{\circ} \mathrm{C}\right) & 410^{\circ} \mathrm{C}<T \leq 445^{\circ} \mathrm{C} \\
\rho_{c} c_{c}=2.566 \times 10^{6}\left(\mathrm{~J} / \mathrm{m}^{3} \cdot{ }^{\circ} \mathrm{C}\right) & 445^{\circ} \mathrm{C}<T \leq 500^{\circ} \mathrm{C} \\
\rho_{c} c_{c}=(0.01603 T-5.44881) \times 10^{6}\left(\mathrm{~J} / \mathrm{m}^{3} \cdot{ }^{\circ} \mathrm{C}\right) & 500^{\circ} \mathrm{C}<T \leq 635^{\circ} \mathrm{C} \\
\rho_{c} c_{c}=(0.16635 T-100.90225) \times 10^{6}\left(\mathrm{~J} / \mathrm{m}^{3} \cdot{ }^{\circ} \mathrm{C}\right) & 635^{\circ} \mathrm{C}<T \leq 715^{\circ} \mathrm{C} \\
\rho_{c} c_{c}=(-0.22103 T+176.07343) \times 10^{6}\left(\mathrm{~J} / \mathrm{m}^{3} \cdot{ }^{\circ} \mathrm{C}\right) & 715^{\circ} \mathrm{C}<T \leq 785^{\circ} \mathrm{C} \\
\rho_{c} c_{c}=2.566 \times 10^{6}\left(\mathrm{~J} / \mathrm{m}^{3} \cdot{ }^{\circ} \mathrm{C}\right) & T>785^{\circ} \mathrm{C}
\end{array}
$$

(3) Coefficient of thermal expansion

$$
\alpha_{c}=(0.008 T+6) \times 10^{-6}\left(\mathrm{~m} / \mathrm{m} \cdot{ }^{\circ} \mathrm{C}\right)
$$

The effect of moisture in the concrete on the column temperatures has been taken into account in the model. Water vapor mostly affects the specific heat capacity of concrete. So according to Ref.[3], specific heat capacity formulas of concrete make the following correction by assuming the quality of water contained in concrete $5 \%$ of the total weight:

$$
\begin{array}{cc}
\rho_{c}^{\prime} c_{c}^{\prime}=0.95 \rho_{c} c_{c}+0.05 \rho_{w} c_{w} & \left(T<100^{\circ} C\right) \\
\rho_{c}^{\prime} c_{c}^{\prime}=\rho_{c} c_{c} & \left(T \geq 100^{\circ} C\right)
\end{array}
$$

Where $\rho_{w}$ and $c_{w}$ are heat density and specific heat of water respectively.

\section{FINITE ELEMENT MODEL}

Because no internal heat source exists in STRC columns, the equation of heat conduction of the member is given below.

$\rho c \frac{\partial T}{\partial t}=k\left(\frac{\partial^{2} T}{\partial x^{2}}+\frac{\partial^{2} T}{\partial y^{2}}+\frac{\partial^{2} T}{\partial z^{2}}\right)$

Before a fire starts, the STRC members are at normal atmospheric temperature. So the initial temperature of members can be assumed equal to the environmental temperature $T_{0}$, that is:

$T(x, y, z, t=0)=T_{0}$

The heat transfer between the faces exposed to fire of STRC columns and the atmospheric temperature proceeds by heat convection and heat radiation. This kind of boundary condition belongs to the third boundary condition. It can be expressed as:

$-k \frac{\partial T}{\partial n}=\alpha_{1}\left(T-T_{f}\right)+\varepsilon \sigma\left[(T+273)^{4}-\left(T_{f}+273\right)^{4}\right]$

In which,

$n$ Normal vector of members' surface.

$\alpha_{1}$ Heat convective coefficient, is taken as $25\left(\mathrm{~W}=\mathrm{m}^{2} \cdot \mathrm{K}\right)$.

$T_{f}$ Temperature of environment $\left({ }^{\circ} \mathrm{C}\right)$.

$\varepsilon$ Heat emissivity coefficient, is taken as 0.5 .

$\sigma$ Stefan-Boltzmann constant, is taken as $5.67 \times 10^{-8}$ $\left(\mathrm{W}=\mathrm{m}^{2} \cdot \mathrm{K}^{4}\right)$.

This paper is concerned with the temperature of STRC columns subjected to ISO-834 standard fire. A finite element analysis model was proposed in this investigation, and ABAQUS FEM program is used in the analysis.

Temperature elevation in STRC columns is governed by the general heat transfer principle. To analyze the threedimensional temperature field of STRC, an 8-node heat transfer linear 3D solid element (DCC3D8D) was used for concrete and a 4-node heat transfer quadrilateral shell element (DS4R) was utilized for the steel hollow section. The "Tie" constraint was selected to simulate the heat transfer between the surface of steel tube and concrete. The influence of steel bars on temperature field was ignored [4]. In the sequent mechanic analysis in and after fire, the temperature of steel bars will be decided through interpolation among concrete nodal temperatures adjacent to the bar. 

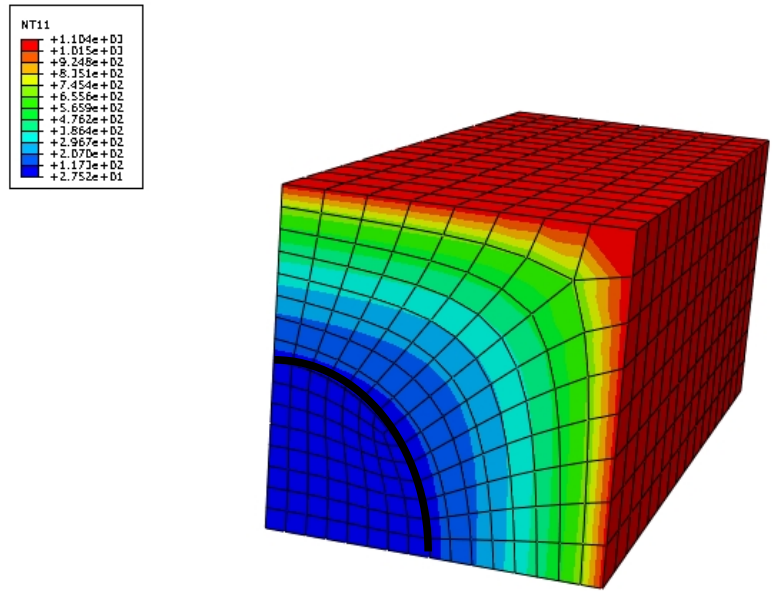

Fig. (2). One example of figure.

According to symmetry, $1 / 2$ or $1 / 4$ section can be adopted to calculate temperature of STRC columns for a symmetrical member. Along the longitude direction, members can also be simplified in concordance with boundary constraint conditions. Typical $1 / 4$ sectional mesh and calculated temperature distributed contours by the method above for STRC columns are shown in Fig. (2).

\section{COMPARISON BETWEEN THEORY AND EXPERIMENTS}

The temperatures within the composite sections predicted by the theoretical model are compared with the test results those obtained from Ref. [1]. Temperature field of two circular tubes reinforced columns were test in Ref. [1]. Specimens were labeled FZ-1 and FZ-2 and all with square section. Sectional dimensions were $B \times D \times t=300 \mathrm{~mm} \times$ $200 \mathrm{~mm} \times 8 \mathrm{~mm}$ and $300 \mathrm{~mm} \times 120 \mathrm{~mm} \times 8 \mathrm{~mm}$ respectively. Where $B$ is the overall tube width, $D$ is the circular tube diameter, $t$ is the tube thickness. The locations of temperature measured were separately at the out surface of steel tube and in the center of section.

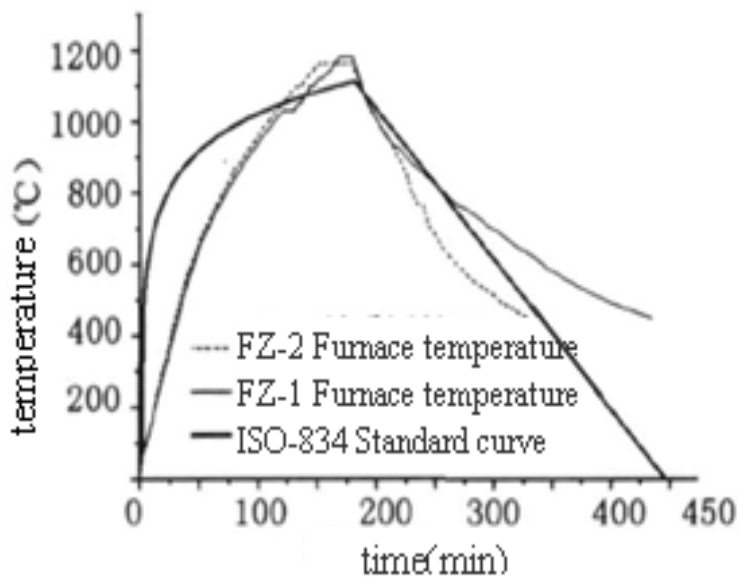

Fig. (3). Relationship between temperature and time.
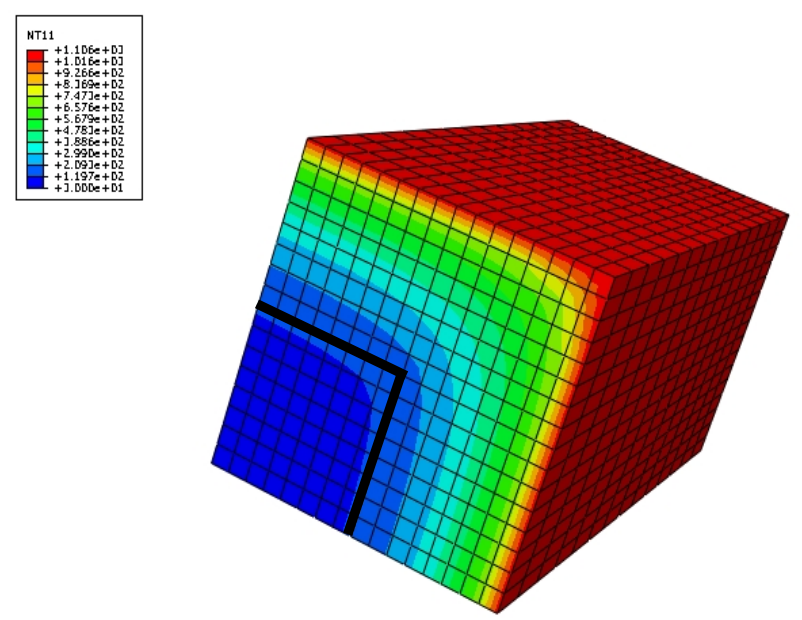

During the test the column was exposed to heating, which was controlled in such a way that the average temperature in the furnace followed as closely as possible the ISO-834 Standard curve (ISO-834, 1975). Fig. (3) shows the measured average furnace temperatures for the two specimens and the ISO-834 Standard curve.

When predict the temperature field of two specimens using the theoretical model, 1/8 members can be adopted according to its symmetry. The ambient temperature increased following actual measured curve.

The comparison between the theoretical prediction of temperatures on the exterior surface of steel tube and in the section center (in solid lines) and experimental temperature (in dashed lines) of STRC columns is shown in Figs. $(\mathbf{4}, \mathbf{5})$. It can be seen that the predicted temperatures show reasonably good agreement with those of the tests.

\section{PARAMETRIC STUDY}

To identify key parameters that mainly influence the temperature field distribution of STRC columns subjected to ISO-834 standard curve, the effects of the following parameters are examined by using numerical results obtained with the theoretical model: temperature rising time $t$, section size $C$ (length of the section perimeter), steel ratio $\alpha_{\mathrm{s}}\left(=A_{\mathrm{s}} / A_{0}\right.$, where $A_{\mathrm{s}}$ and $A_{0}$ are the cross-sectional areas of steel tube and total-cross-section respectively), sectional core area ratio $\alpha_{\mathrm{sc}}\left(=A_{\mathrm{sc}} / A_{0}\right.$, where $A_{\mathrm{sc}}$ is the cross-sectional area of steel tube and concrete in it, $A_{0}$ is the cross-sectional areas of totalcross-section).

\subsection{Effect of Temperature Rising Time}

The exterior surface temperature of the steel tube $\left(T_{1}\right)$ and the temperature of the centre of the cross-section $\left(T_{2}\right)$ and the exterior surface temperature of the member $\left(T_{3}\right)$ are chosen as examples to show the effect of temperature rising time. The temperatures versus the time $(t)$ are plotted in Fig. (6) for the column with the section perimeter $(C)=2400 \mathrm{~mm}$. 


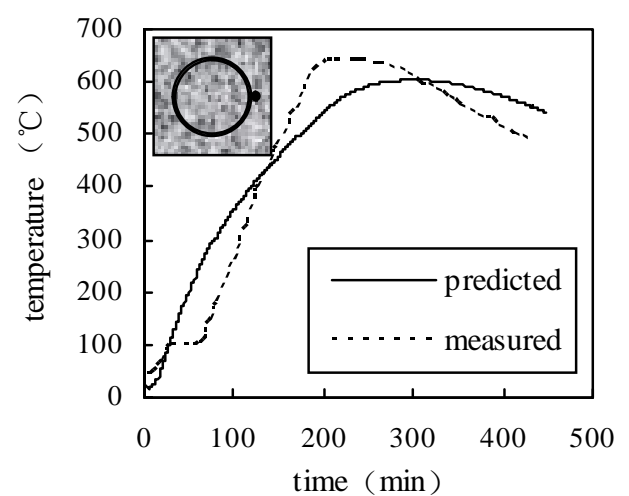

a) Exterior surface temperature of steel tube

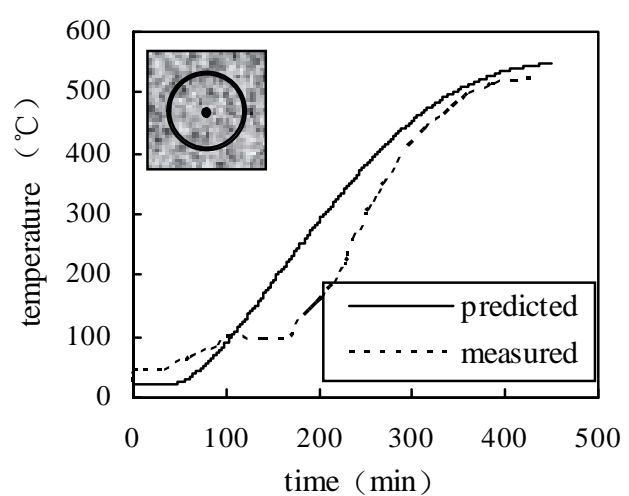

b) Sectional center temperature

Fig. (4). Comparison between calculated and measured temperature distribution of FZ-1 columns.

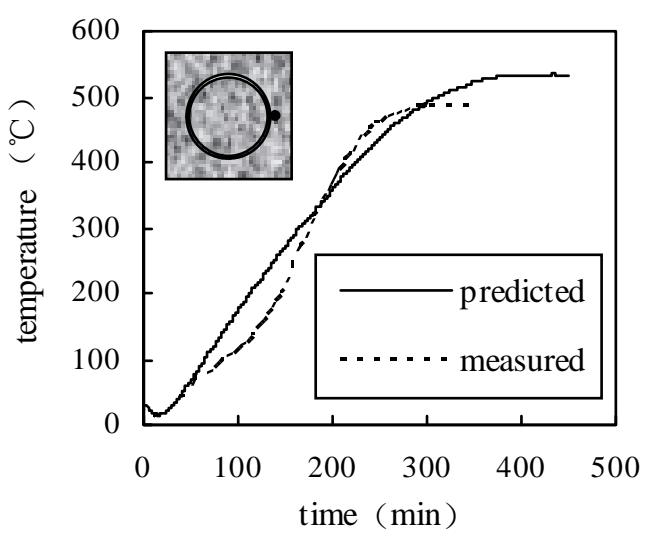

a) Exterior surface temperature of steel tube

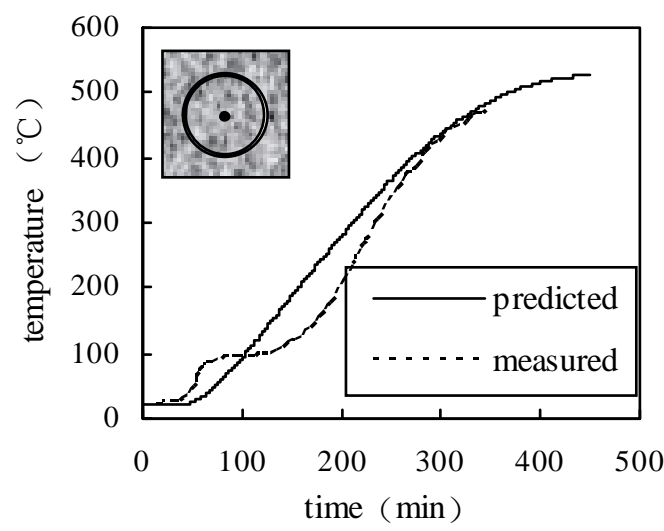

b) Sectional center temperature

Fig. (5). Comparison between calculated and measured temperature distribution of FZ-2 columns.

The ISO standard curve is also shown in Fig. (6) for comparison.

It can be found that the surface temperature of STRC columns increases obviously with the environmental

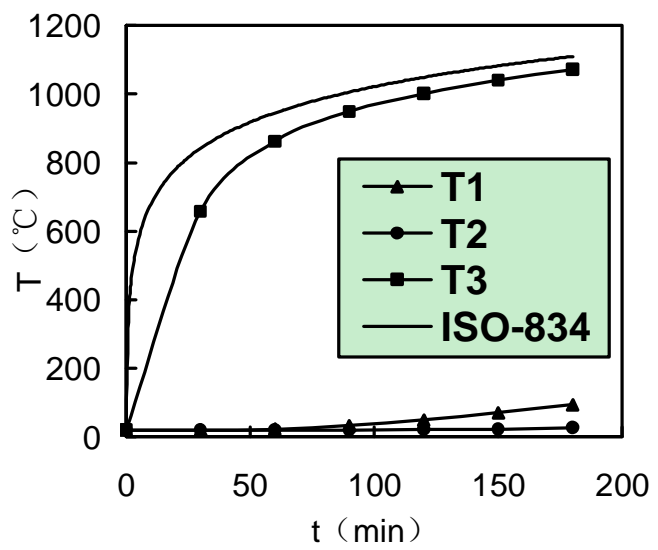

Fig. (6). Effect of temperature elevated time on temperature field. temperature rising. The longer exposed to fire, the closer to environmental temperature it is. Because of the insulation of outer concrete layer, the temperatures of steel tubes and core concrete increase slowly, and they are all lower than $100^{\circ} \mathrm{C}$ within a three hour fire time for the column.

\subsection{Effect of Section Size}

The exterior surface temperature of the steel tube $\left(T_{1}\right)$ and the temperature of the centre of the cross-section $\left(T_{2}\right)$ are chosen as examples to show the effect of section dimensions. The temperatures versus the section perimeter $(C)$ of the STRC sections are plotted in Fig. (7) for $\mathrm{t}=60,120,180$ $\min$.

It can be found that the larger the section dimensions the lower the temperature is. The effect of section dimensions on temperature reduction is significant both for the section center and for the steel out surface. The reduction in temperature due to the increase of dimensions becomes less significant when $C$ exceeds a certain range (about $\mathrm{C}=2000 \mathrm{~mm}$ ). 


\subsection{Effect of Steel Ratio}

The out surface temperature of the steel tube $\left(T_{1}\right)$ and the temperature of the centre of the cross-section $\left(T_{2}\right)$ are chosen as examples to show the effect of steel ratios. The temperatures versus the steel ratio $\left(\alpha_{\mathrm{s}}\right)$ of the STRC sections are plotted in Fig. (8) for $\mathrm{t}=60,120,180 \mathrm{~min}$. It can be found that the influence of steel ratio on steel tube and section core temperature reduction is less.

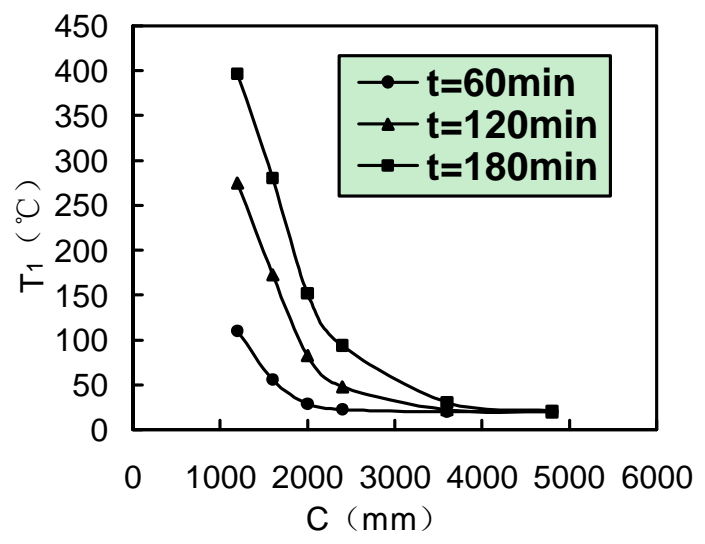

Fig. (7). Effect of sectional perimeter on temperature field.

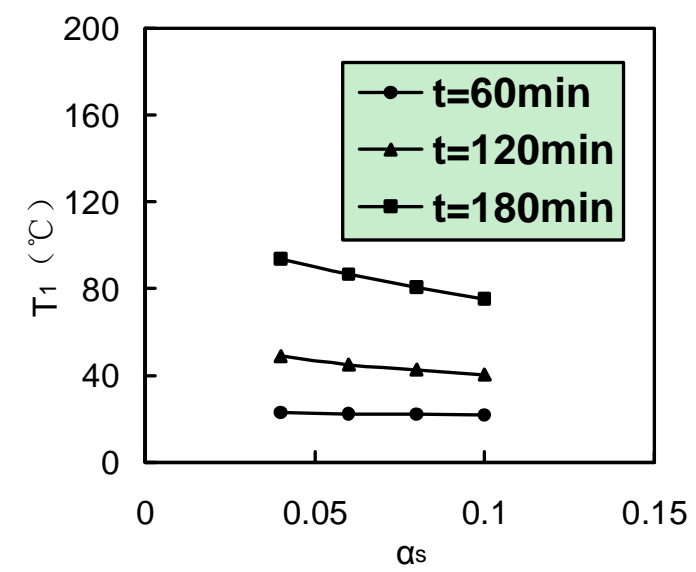

Fig. (8). Effect of steel ratio on temperature field.

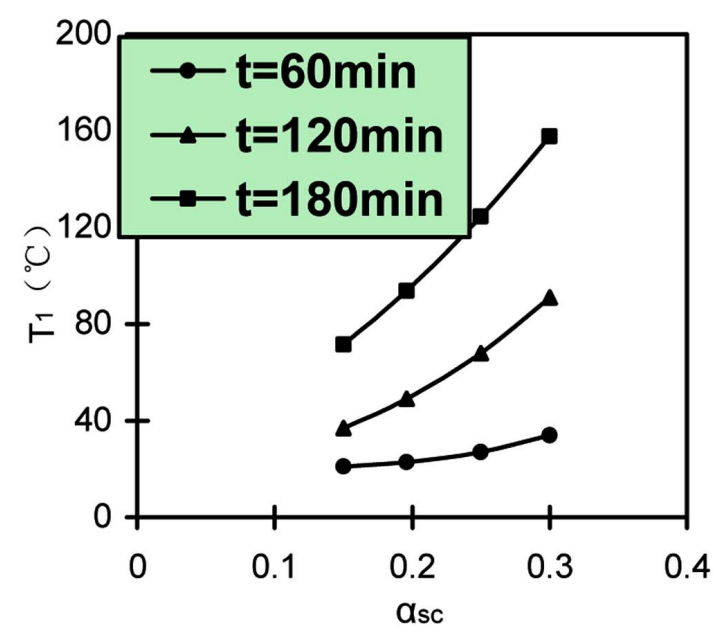

Fig. (9). Effect of sectional core area ratio on temperature field.

\subsection{Effect of Sectional Core Area Ratio}

The concrete outside steel tube would be an insulating layer to steel tube and inside core concrete in fire. The thicker outside concrete layer the lower steel tube temperature is. The parameter of sectional core area ratio $\alpha_{\mathrm{sc}}$ of the STRC sections reflects the thickness of outside concrete insulating layer, so it is an important influencing factor for the temperature field of STRC columns.
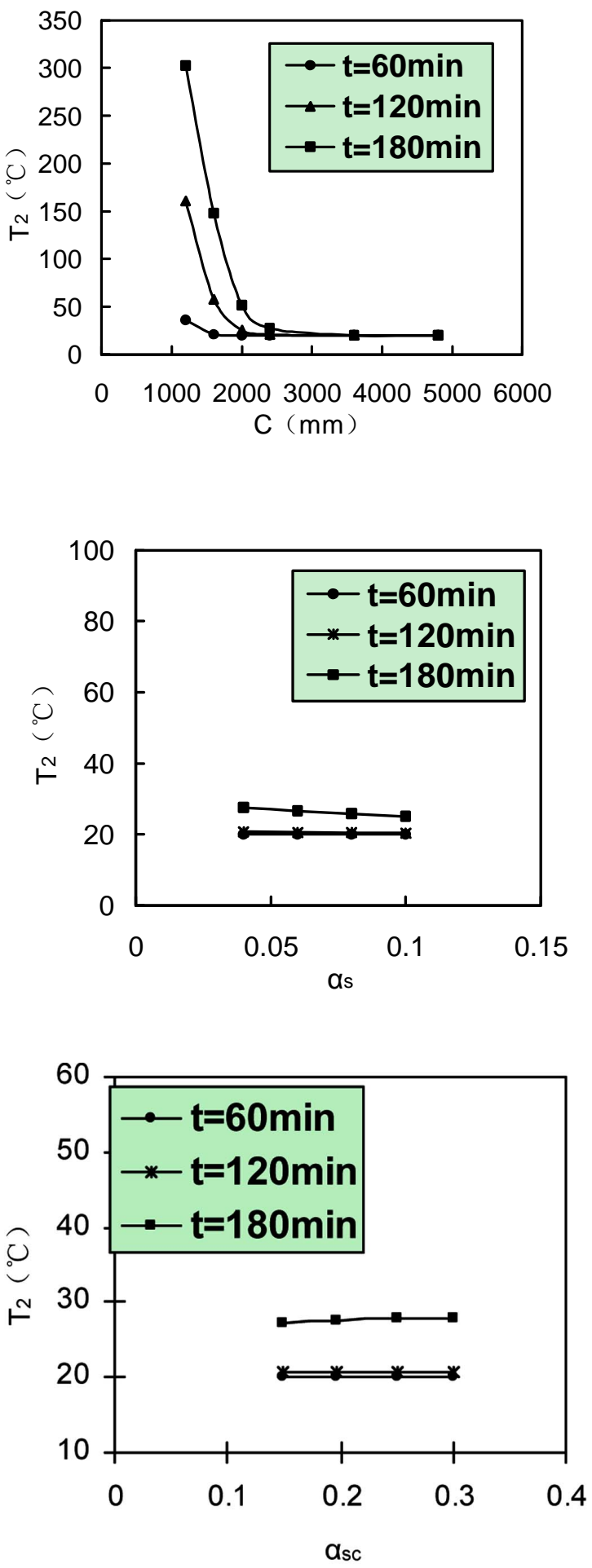
The out surface temperature of the steel tube $\left(T_{1}\right)$ and the temperature of the centre of the cross-section $\left(T_{2}\right)$ are chosen as examples to show the effect of sectional core area ratios. The temperatures versus the sectional core area ratio $\alpha_{\mathrm{sc}}$ of the STRC sections are plotted in Fig. (9) for $\mathrm{t}=60,120,180$ $\min$.

It can be found that the effect of sectional core area ratios on temperature of steel tube is significant within a three hour fire time. The thickness of outside concrete layer decreased with the increase of sectional core area ratio, so the temperature of steel tube is increasing significantly. But in three hours, the increase of sectional center temperature due to the increase in sectional core area ratio is less. The temperature in sectional center is slightly higher initial temperature.

\section{CONCLUSION}

Based on the results and discussions presented in this paper, the following conclusions can be drawn: (1) Nonlinear finite element analysis has been carried out to calculate the temperature field for STRC members. The theoretical predictions in this paper are in good agreement with the experimental data. (2) The surface temperature of STRC columns increases obviously with the environmental temperature rising. The longer exposed to fire, the closer to environmental temperature it is. Because of the insulation of outer concrete layer, the temperatures of steel tubes and core concrete increase slowly. (3) The effects of section size and sectional core area ratio on temperature field are significant. But steel ratio has very little effect on temperature both of steel tube and of sectional center. (4) The increase in section dimension results in a temperature reduction within the section, whereas the reduction in temperature becomes less significant when $C$ exceeds a certain range. (5) The increase in sectional core area ratio results in a temperature increase within the section. The effect of sectional core area ratios on temperature of steel tube is significant. But the increase of sectional center temperature due to the increase in sectional core area ratio is less, and the temperature in sectional center is slightly higher initial temperature.

\section{CONFLICT OF INTEREST}

Declared none.

\section{ACKNOWLEDGEMENTS}

The research reported in the paper is part of the Project 50908035 supported by National Natural Science Foundation of China.

\section{REFERENCES}

[1] Y.H. Feng, T. Shen, W.J. Lou and J. Zhou, "The study of residual load bearing capacity of alumina reinforced by unier circular steel tube after fire", Ind. Constr., vol. 38, pp. 16-19, June 2008.

[2] T.T. Lie and E.M.A. Denham. "Factors Affecting the Fire Resistance of Square Hollow Steel Columns Filled with Barreinforced Concrete", NRC-CNRC Internal Report \# 651, National Research Council, Canada, 1993.

[3] L.H. Han, Concrete-Filled Steel Tubular Structures. Science Press: Peking, China, 2004.

[4] Z.H. Guo and X.D. Shi, Performance and Calculation under High Temperature of Reinforced Concrete, Tsinghua University Press, Peking, China, 2003. 